\title{
The degradation mechanism of an epoxy-phenolic can coating
}

DOI:

10.1016/j.porgcoat.2016.03.019

\section{Document Version}

Accepted author manuscript

Link to publication record in Manchester Research Explorer

\section{Citation for published version (APA):}

Morsch, S., Lyon, S., \& Gibbon, S. R. (2017). The degradation mechanism of an epoxy-phenolic can coating. Progress in Organic Coatings, 102, 37-43. https://doi.org/10.1016/j.porgcoat.2016.03.019

\section{Published in:}

Progress in Organic Coatings

\section{Citing this paper}

Please note that where the full-text provided on Manchester Research Explorer is the Author Accepted Manuscript or Proof version this may differ from the final Published version. If citing, it is advised that you check and use the publisher's definitive version.

\section{General rights}

Copyright and moral rights for the publications made accessible in the Research Explorer are retained by the authors and/or other copyright owners and it is a condition of accessing publications that users recognise and abide by the legal requirements associated with these rights.

\section{Takedown policy}

If you believe that this document breaches copyright please refer to the University of Manchester's Takedown Procedures [http://man.ac.uk/04Y6Bo] or contact uml.scholarlycommunications@manchester.ac.uk providing relevant details, so we can investigate your claim.

\section{OPEN ACCESS}




\section{The Degradation Mechanism of an Epoxy- Phenolic Can Coating}

S. Morsch ${ }^{*},{ }^{1}$ S. Lyon, ${ }^{1}$ S. R. Gibbon ${ }^{2}$

${ }^{1}$ Corrosion and Protection Centre,

School of Materials,

The University of Manchester,

The Mill,

Sackville St,

Manchester, M13 9PL, UK

${ }^{2}$ AkzoNobel Supply Chain, Research \& Development,

Stoneygate Lane,

Felling,

Gateshead,

Tyne \& Wear, NE10 0JY, UK

${ }^{*}$ To whom correspondence should be addressed. Suzanne.morsch@manchester.ac.uk tel: +44 1613062914 


\section{ABSTRACT}

Paint remains a widely employed approach to corrosion control due its relatively low cost and proven efficacy. Nonetheless, the processes governing long-term deterioration of intact organic coatings (in the absence of defects) are not fully understood. In this contribution, we investigate the degradation mechanism of a corrosion resistant epoxyphenolic can coating. In-situ time-resolved ATR FTIR is applied to monitor both the chemical integrity of the coating and water uptake as a function of immersion time in water or electrolyte. Ion transport is assessed across free standing films, and morphological changes accompanying immersion are examined using ex-situ advanced scanning probe microscopy techniques. Coatings are found to deform as a result of water sorption during immersion in electrolyte or water, yielding regions of heterogeneous hydrophilicity, yet no change in functional group chemistry is found to occur.

\section{HIGHLIGHTS}

- Immersion in water or electrolyte does not affect the chemical structure of an epoxy-phenolic can-coating.

- Ionic transport occurs across free-standing films independently of water-induced damage.

- Non-Fickian water sorption is associated with deformation of the coating.

- AFM-IR is used to show that hydrophilic pores form during immersion. 


\section{INTRODUCTION}

Paint remains the most widely employed approach to corrosion control due its relatively low cost and proven efficacy. Nevertheless, the long-term deterioration of coating barrier properties (associated with the onset of underfilm corrosion) is not fully understood, and continues to be a matter of significant scientific and industrial interest. For organic coatings, it is widely accepted that failures in corrosion protection are most commonly instigated by the presence of a defect traversing the film (as a consequence of e.g., mechanical damage during the coating lifetime, inconsistent application, or trapped solvent during the cure). Consequently, research efforts have focussed on corrosion initiation in the presence of macroscopic defects, and coatings are routinely formulated to mitigate corrosive phenomena at and around defect sites (by e.g., the inclusion of leachable inhibitor additives).[1-7] Little attention has been paid to the long-term failure of intact organic coatings, a process which becomes increasingly significant as formulation and application techniques continue to improve. In the case of intact organic coatings, it can be seen that any long term failure in corrosion protection must involve the spontaneous degradation of polymeric barrier properties, yet the mechanism of this process remains elusive.

At present, the prevailing model describing the long term degradation of intact organic coatings entails the spontaneous formation of conducting pathways through the coating, followed by localised corrosion initiation (i.e., the base of the ionic pathway behaves in the same manner as a macroscopic defect), Scheme 1. Nguyen proposed that in the presence of neutral electrolyte, these ionic transport pathways are introduced by the action of water during immersion; via hydrolysis reactions, leaching of unreacted material or else the gradual evolution of hydrophilic channels traversing the film.[8] In the case of epoxy resins, (widely used as the binders in corrosion resistant paints) little evidence exists for hydrolytic breakdown under ambient conditions, and in particular for food-contact epoxyphenolic coatings (such as those studied here) negligible leaching effects have been well documented.[9-12] Thus, hydrophilic (and ionic) transport pathways are considered to evolve spontaneously in the absence of chain scission or leaching phenomena, and result in localised failures. However, whilst this mechanism of degradation was proposed in the Nguyen model almost two decades ago, few studies have addressed the formation of discrete hydrophilic or ionic transport channels through intact coatings. Taylor et al have previously reported evidence for ionic transport pathways through epoxy coatings, detected using fluorescence microscopy (after aging in electrolyte and exposure to an ion-specific fluorescent probes, or directly using cationic chromophores). $[13,14]$ In addition, we recently reported the first direct observations of heterogeneous water sorption into epoxy-phenolic 
coatings using the newly developed AFM-IR technique.[15,16] It was found that water diffusion into films is initially heterogeneous, and that prolonged immersion in deionised water yields localised deformation and swelling. This supports a picture of water-induced damage as the first stage of coating deterioration. However, Leidheiser and others have previously proposed that upon immersion in electrolyte, alkali cations may also play a direct role in the degradation of organic coatings by inducing localised morphological changes via ion exchange reactions or mass action, yielding ionic transport pathways[17,18]. Therefore, in the present contribution, we investigate and compare the effects of immersion in both electrolyte and deionised water for an epoxy-phenolic can coating. In-situ time-resolved FTIR is first applied to assess the chemical integrity of an epoxy-phenolic can-coating during immersion, then the morphological changes accompanying immersion are characterised using ex-situ microscopy.

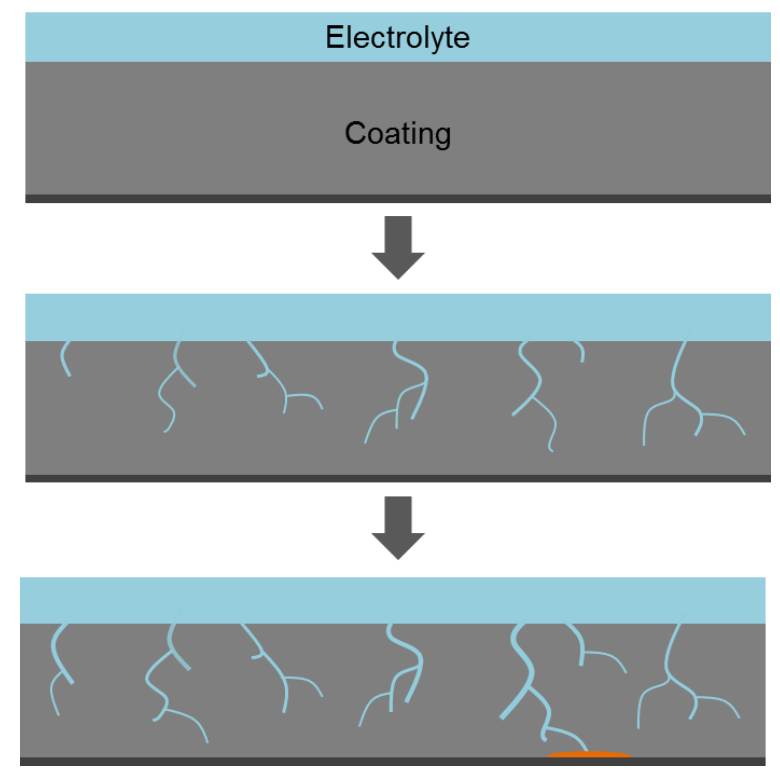

Scheme 1: The Nguyen model of intact coating degradation. Hydrophilic pathways develop during water sorption from the electrolyte into organic coatings, and these eventually widen to form ionic transport channels connecting the substrate and electrolyte, enabling localised underfilm corrosion. 


\section{EXPERIMENTAL}

\subsection{Sample Preparation}

Electrolytic chrome-coated steel pieces $\left(4 \mathrm{~cm}^{2}\right)$ were degreased by rinsing in ethanol (Fisher Scientific, >99\%). Thin films of epoxy-phenolic Vitalure 345 Lacquer (AkzoNobel Packaging Coatings, Birmingham, UK) were then cast onto the steel pieces at $2000 \mathrm{rpm}$ for $30 \mathrm{~s}$ (Photoresist spin coater, Headway Research Inc., 1-10,000 rpm). Specimens were cured by placing in an oven maintained at $200{ }^{\circ} \mathrm{C}$ for $15 \mathrm{~min}$, resulting in a dry film thickness of $4.3 \pm$ $0.3 \mu \mathrm{m}$. Free-standing films were acquired by delamination from PTFE (Polyflon). PTFE films were first attached to steel substrates, then coated and cured under identical conditions.

\subsection{Film Characterisation}

For infrared analysis the epoxy-phenolic lacquer was manually bar coated (using an $8 \mu \mathrm{m}$ spiral bar, Elcometer) onto a germanium internal reflection element and cured for $15 \mathrm{~min}$ at $200{ }^{\circ} \mathrm{C}$. In order to assess water uptake, $5 \%$ (w/w) NaCl solution in $\mathrm{D}_{2} \mathrm{O}$ (>99 \%, Aldrich) was prepared and injected into an ATR fluid cell, forming a reservoir against the coating, Scheme 1. Using this set up, infrared spectra can be gathered continuously without adjustment of the sample or realignment of the laser. Spectra are the result of 32 accumulations collected in ATR mode (with a $45^{\circ}$ angle of incidence) using an FTIR spectrometer (Spectrum 2000, Perkin Elmer), operating at $4 \mathrm{~cm}^{-1}$ resolution across the 700 $4000 \mathrm{~cm}^{-1}$ range. FTIR spectra were gathered every 60 min over a ten day period.

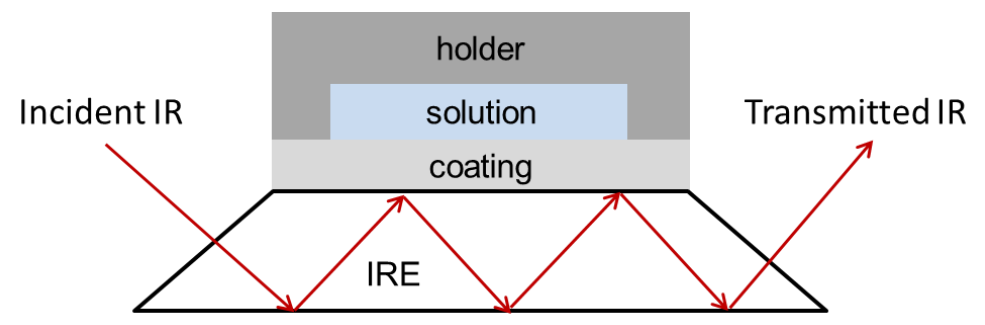

Scheme 2. The ATR fluid cell set-up with a germanium internal reflection element (IRE) used for insitu immersion FTIR measurements.

Atomic force microscope images were obtained using a Multimode 8 (Bruker, Santa Barbara) operating in Peakforce Nanomechanical mode using a Pt-Ir coated SCMPIT probe (Bruker, nominal spring constant $2 \mathrm{~N} / \mathrm{m}$, nominal resonance frequency of $80 \mathrm{kHz}$ ). 
Nanoscale infrared analysis was performed on a NanolR2 system (Anasys Instruments) operating with top-down illumination. During AFM-IR, the sample is subjected to rapid pulses (10 ns duration at a repetition rate of $1 \mathrm{KHz}$ ) from a tuneable infrared source (optical parametric oscillator). Absorbance of infrared radiation induces abrupt thermal expansion of the sample, and this is detected by deflection of an AFM probe in contact with the surface. The recorded AFM-IR signal is either the maximum of peak-to-peak deflection during the cantilever ring-down corresponding to IR pulses, or the amplitude of induced oscillation after fast Fourier transform, Scheme 3. It has been shown that plotting these signals as a function of IR wavelength yields spectra closely matched to those obtained by macroscopic transmission-mode FTIR.[19] Furthermore, since the IR pulse (10 ns duration), thermal expansion, and damping down of the induced oscillation occur on a faster timescale than the feedback electronics of the AFM, simultaneous contact-mode topographical measurement and IR absorbance mapping can be performed at a given wavelength. [20-23] For the present study, AFM-IR images were collected in contact mode at a scan rate of 0.1 $\mathrm{Hz}$ using a gold-coated silicon nitride probe $(0.07-0.4 \mathrm{~N} / \mathrm{m}$ spring constant, $13 \pm 4 \mathrm{kHz}$ resonant frequency, Anasys Instruments). For mapping, the amplitude of the induced vibration was recorded at a given wavelength using 16 co-averages for 1024 points per 300 scan lines. The specimen and AFM head were contained within a sample chamber equipped with a portable temperature and humidity logger (Lascar Electronics). In order to raise humidity, saturated $\mathrm{NaCl}$ solution in $\mathrm{D}_{2} \mathrm{O}$ was placed in a recrystallizing dish within the sample chamber and allowed to equilibrate for $24 \mathrm{~h}$.
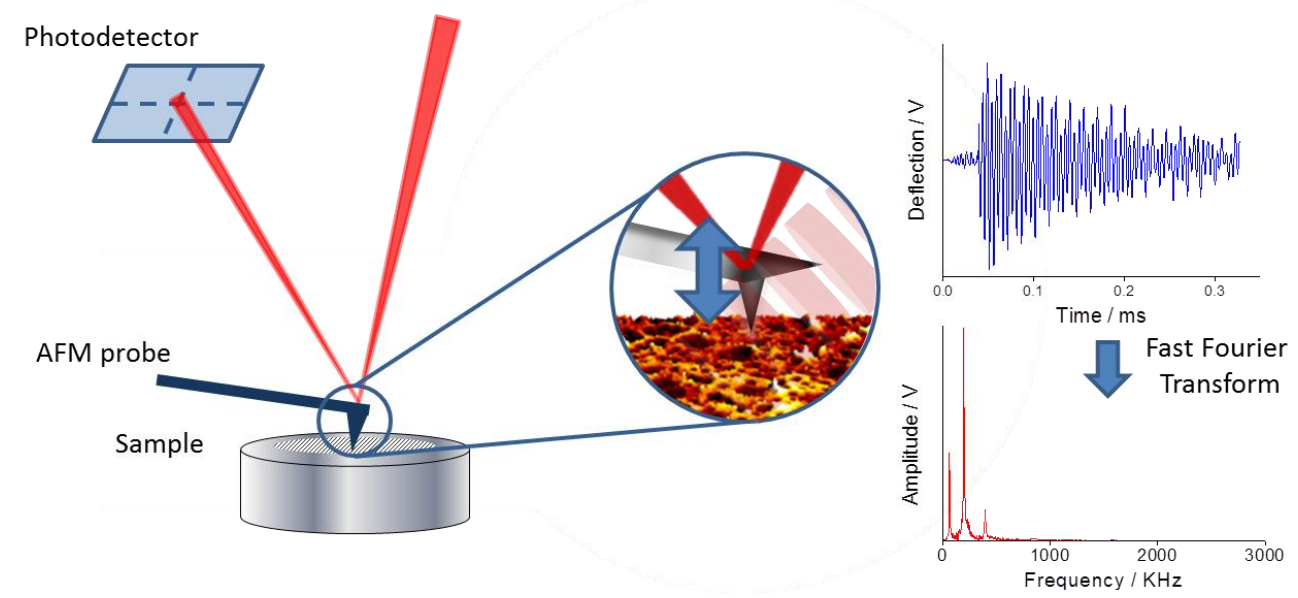

Scheme 3. The AFM-IR experiment with top-down illumination. The infrared source is pulsed, inducing rapid thermal expansion of the sample, detected by deflection of the AFM probe cantilever. The recorded AFM-IR signal is either given as the maximum peak-to-peak deflection during the cantilever ring-down following $10 \mathrm{~ns}$ infrared pulses, or the amplitude at a given frequency following a fast Fourier transform of the deflection signal. 


\section{RESULTS}

\subsection{In-situ FTIR Analysis}

The chemical integrity of epoxy phenolic coatings was initially evaluated using in-situ ATR FTIR spectroscopy in the presence of electrolyte. Spectra were collected at 60 min intervals over a period of 10 days, commencing directly after injection of a $5 \% \mathrm{w} / \mathrm{w}$ solution of $\mathrm{NaCl}$ in $\mathrm{D}_{2} \mathrm{O}$ into the ATR fluid cell, Scheme 2. It is notable that infrared absorbance in the fingerprint region associated with polymeric functionality $\left(700-2000 \mathrm{~cm}^{-1}\right)$ remained unaffected throughout exposure to the electrolyte environment, confirming that the coatings do not delaminate during exposure (since coating peak intensity would be expected to diminish following delamination, due to an effectively lowered concentration within the infrared evanescent wave sampling depth).[24] In addition, during exposure the appearance (and then incremental increase) of a broad absorbance centred around $2550 \mathrm{~cm}^{-1}$ was observed, Figure 1a. This band is attributed to the O-D stretch of deuterium oxide absorbed by the epoxy-phenolic coating from the electrolyte solution.[25] Again, the position and intensity of peaks in the spectral fingerprint region remained completely unchanged in the presence of this absorbed water, confirming that no disruption of macromolecular structure occurs due to bulk hydrolysis reactions, Figure 1 a.

Because the infrared absorbance of the O-D stretch vibration does not overlap with any native infrared peaks associated with the epoxy-phenolic polymer, moisture uptake into the coating is directly proportional to the absorbance increase in this region, and was quantified by integration of the $2550 \mathrm{~cm}^{-1}$ band at each time point. For comparison, a second experiment was also performed using only deuterium oxide as the exposure medium, and the measured area of the O-D stretch bands were normalised relative to the area of the entire fingerprint region in both cases, Figure 1b. A degree of noise is generated in water sorption profiles by fluctuating $\mathrm{CO}_{2}$ bands (centred on $2280 \mathrm{~cm}^{-1}$ ), which overlap with the broad O-D stretch band. Nonetheless, it is clear that water sorption occurs in both cases, and from generated profiles it can be seen that significantly enhanced water sorption occurs in the presence of $\mathrm{D}_{2} \mathrm{O}$. This is in keeping with previous reports, where the kinetics and equilibrium content for water uptake into epoxy resins has been found to depend on the water activity of the immersion medium.[26]

It is well-known that water sorption kinetics correlate to the transport mechanism through organic networks. In general, Fickian diffusion is associated with fast polymer relaxation or rapid sorption into the available free volume (i.e., diffusion limited by mobility of 
the penetrant solvent), whereas non-Fickian kinetics is associated with polymeric relaxation and penetration into the bulk (i.e., transport is limited by the mobility of polymer segments) [27-30] In the present case, for moisture sorption from electrolyte, the reduced time plot indicates Fickian diffusion at early exposure times ( $<4 \mathrm{~h}$, a linear correlation is evident), Figure 2a. At longer exposure times, it can be seen that the kinetics deviate from ideal Fickian behaviour; i.e., an equilibrium water content is not established, and instead water uptake continues at a slower rate, characteristic of non-Fickian diffusion. Such two-stage water sorption kinetics are typical for epoxy resins, where water is proposed to rapidly penetrate the available free volume via Fickian diffusion, whilst relaxation of waterplasticised polymer chains drives further, slower sorption by exposing further hydrogen bonding sites and isolated pockets of free volume. Moreover, two-stage kinetics are consistent with previous water sorption results for these epoxy phenolic coatings, where it has been shown that rapid water sorption under humid conditions initially occurs via diffusion into the available free volume (60 min exposure time)[31], whereas deformation occurs only after longer term (3 days) immersion in water (swelling and deformation are associated with non-Fickian sorption, since this process involves disruption of the network)[15].

For water sorption directly from $\mathrm{D}_{2} \mathrm{O}$, no Fickian diffusion stage was detected (no linear correlation is observed in the reduced time plot), Figure $2 \mathrm{~b}$. We propose this is because the initial rapid penetration into the available free volume occurs prior to the first measured time point (60 min). Instead, the kinetic profile is characteristic of an autoaccelerated process (S-shaped curve). This can be attributed to water-plasticised polymer relaxation (i.e., the presence of absorbed water accelerates the non-Fickian sorption process). Indeed, we have previously reported water plasticisation of these epoxy-phenolic can coatings, where the measured $\mathrm{T}_{\mathrm{g}}$ was depressed by $4{ }^{\circ} \mathrm{C}$ (from $89{ }^{\circ} \mathrm{C}$ to $85^{\circ} \mathrm{C}$ ) after 7 days immersion in deionised water and drying.[15]

Since the penetration depth of the evanescent wave for a germanium internal reflection element at $2550 \mathrm{~cm}^{-1}$ can be calculated to be $<500 \mathrm{~nm}$ [32], a further notable result for FTIR experiments is the rapid penetration of water through the entirety of the (nominally 8 $\mu \mathrm{m}$ thick) coatings (<60 $\mathrm{min}$ ), demonstrating that water can freely diffuse through the intact coating structure. To assess whether this could be accompanied by ion transport when the immersion medium is electrolyte, permeation experiments were undertaken. $4.9 \mathrm{~cm}^{2}$ free standing films were used to separate $10 \mathrm{~g} 5 \% \mathrm{w} / \mathrm{w} \mathrm{NaCl}$ electrolyte and $150 \mathrm{~g}$ deionised water in a sealed vessel, Scheme 4 . Conductivity of the water was then monitored over a ten day period, Figure 3. Despite significant sample-to-sample variation, it can be seen that the conductivity of the surrounding solution consistently rises, indicating that ion transport is possible across intact free-standing films. To ensure that this was not the result of 
contamination during measurement, or leaching from the coating, a control experiment was also performed using only deionised water, Scheme 4 and Figure 3 . It can be seen that the measured conductivity remained consistently low in this case.
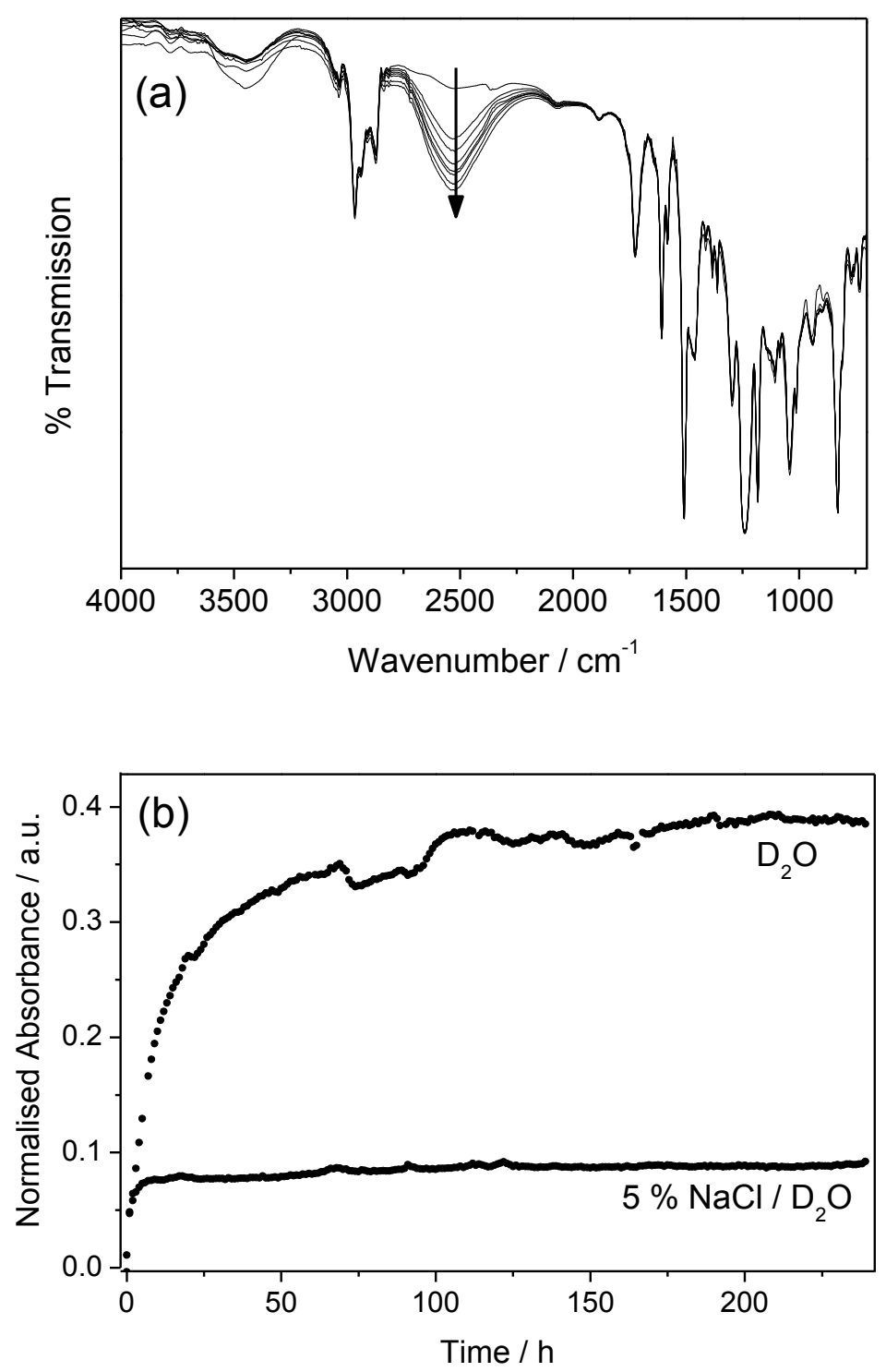

Figure 1. (a) In situ ATR FTIR spectra of epoxy-phenolic coating immediately after injection of $5 \%$ $\mathrm{w} / \mathrm{w} \mathrm{NaCl}$ solution in $\mathrm{D}_{2} \mathrm{O}$ into the fluid cell, and after $1 \mathrm{~h}, 2 \mathrm{~h}, 4 \mathrm{~h}, 9 \mathrm{~h}, 18 \mathrm{~h}, 68 \mathrm{~h}$ and $120 \mathrm{~h}$ exposure time; (b) absorbance increase of the O-D stretch band (normalised to the fingerprint region) as a function of exposure time to $5 \% \mathrm{w} / \mathrm{w} \mathrm{NaCl}$ solution in $\mathrm{D}_{2} \mathrm{O}$, and $\mathrm{D}_{2} \mathrm{O}$. 


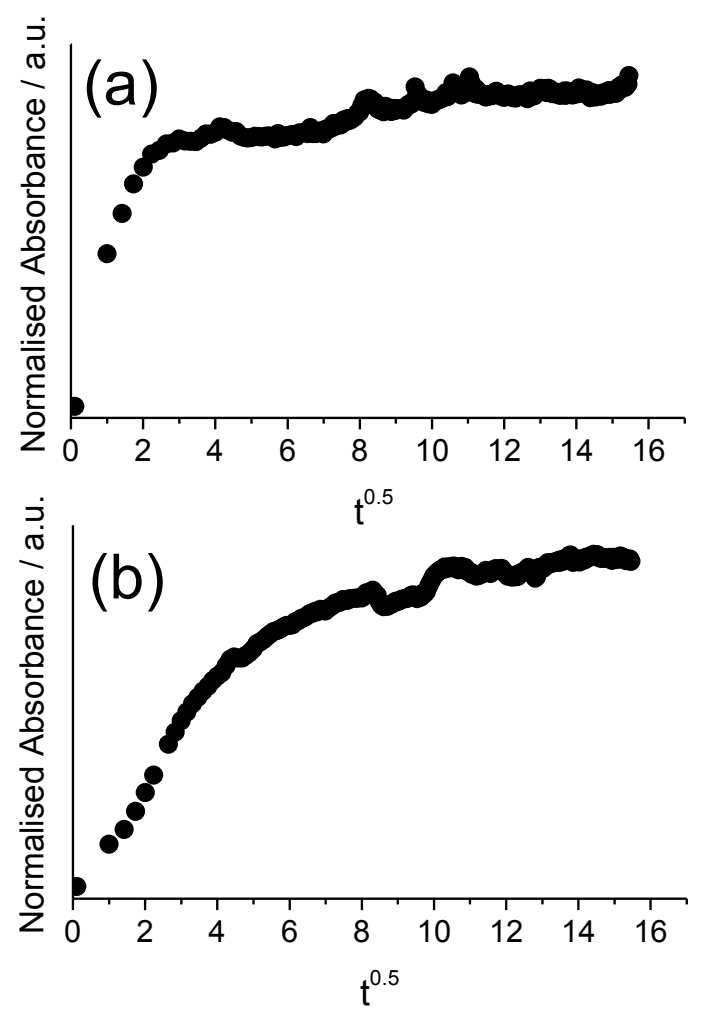

Figure 2. Reduced time plots of absorbance for the O-D band (normalised to the fingerprint region) as a function of $t^{0.5}$, where $t$ is exposure time to (a) $5 \% \mathrm{w} / \mathrm{w} \mathrm{NaCl}$ solution in $\mathrm{D}_{2} \mathrm{O}$ and (b) $\mathrm{D}_{2} \mathrm{O}$. 


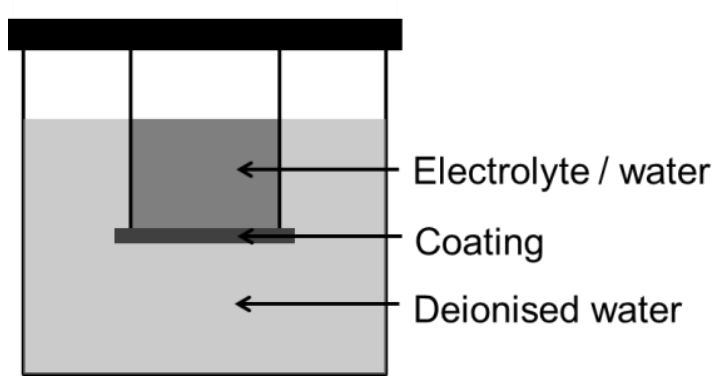

Scheme 4. Experimental setup for ion permeation experiment.

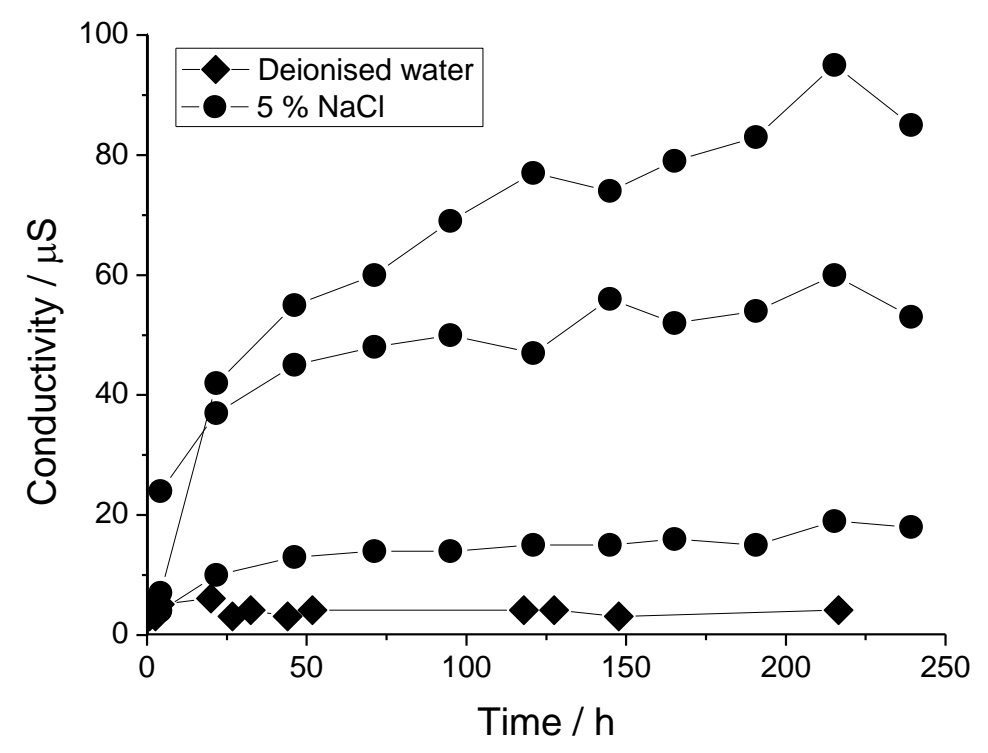

Figure 3. Measured conductivity of $150 \mathrm{~g}$ deionised water separated from $10 \mathrm{~g} 5 \% \mathrm{w} / \mathrm{w} \mathrm{NaCl}$ (circles) or deionised water (diamonds) by free-standing epoxy-phenolic can coating films, as a function of time. 


\subsection{Ex-situ Characterisation}

To characterise morphological changes accompanying water sorption and ion penetration, the coatings were examined under humid conditions $\left(70 \% \mathrm{RH}\right.$ at $\left.26{ }^{\circ} \mathrm{C}\right)$ using peakforce mode AFM imaging immediately after immersion in $5 \% \mathrm{w} / \mathrm{w}$ aqueous $\mathrm{NaCl}$ electrolyte or deionised water for periods of 7 days and 21 days (samples were briefly air dried prior to being transferred to the microscope), Figure 4. In all cases deformation is apparent after immersion, with roughened porous morphologies developing at the coating surface. To exclude leaching as a source of this porosity, gravimetric experiments were performed; coating mass was accurately assessed for free standing films before and after immersion in deionised water for 7 days followed by 2 days drying in a desiccator. No loss of coating mass was measured; $(+0.2 \% \pm 0.1 \%$ weight change) confirming that leaching of unreacted or hydrolysed material is not significant for these coatings.

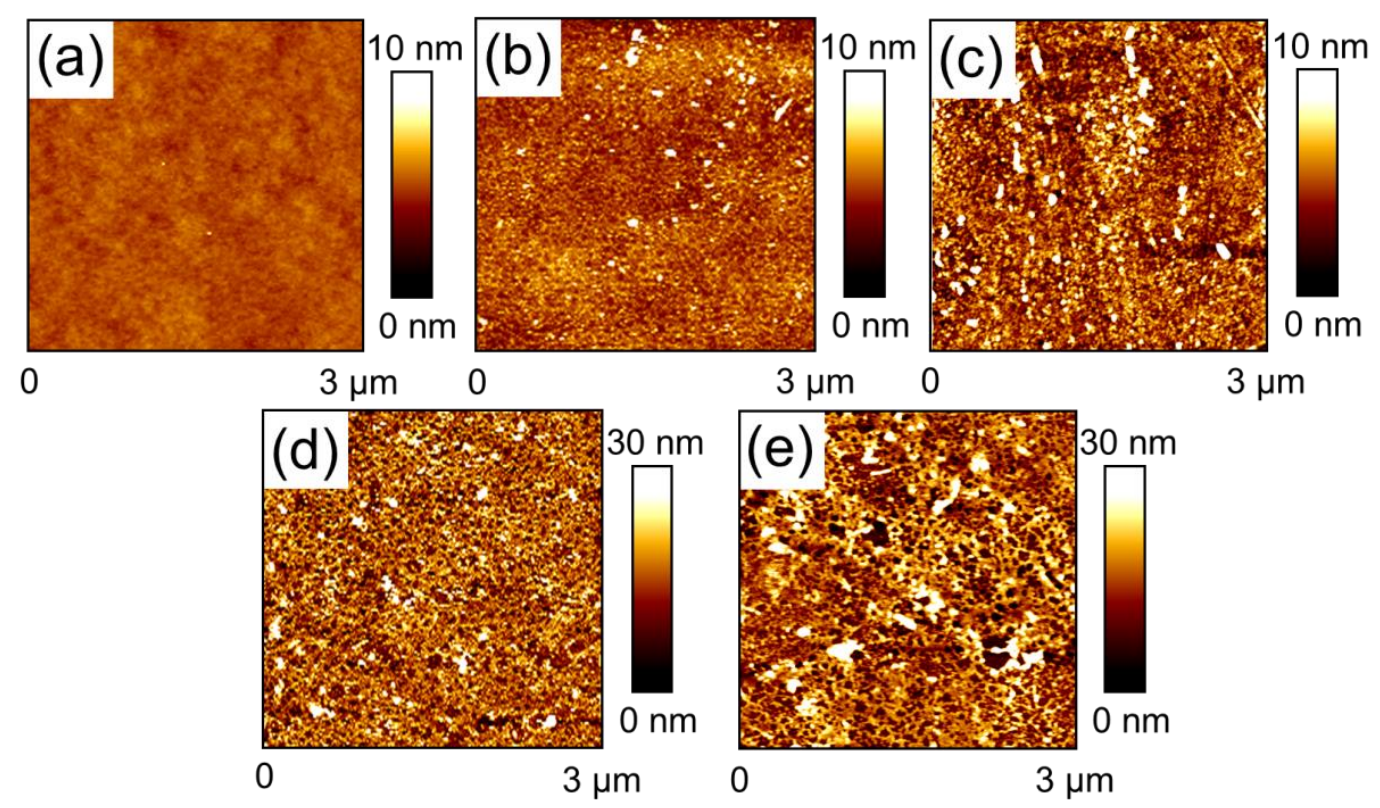

Figure 4. Peakforce tapping mode AFM height profiles of epoxy-phenolic coatings on polished carbon steel (a) as deposited; (b) after 7 days immersion in $5 \% \mathrm{w} / \mathrm{w} \mathrm{NaCl}$ electrolyte; (c) after 21 days immersion in $5 \% \mathrm{w} / \mathrm{w} \mathrm{NaCl}$ electrolyte; (d) after 7 days immersion in deionised water and (e) after 21 days immersion in deionised water. 
Finally, AFM-IR analysis was applied to determine the relative hydrophilicity across the deformed coatings. The specimen displaying the greatest degree of morphological disruption was selected, i.e., that pre-soaked in deionised water for 21 days. Localised water sorption was assessed by monitoring the O-D stretch absorbance at $2550 \mathrm{~cm}^{-1}$ before and after exposure to $\mathrm{D}_{2} \mathrm{O}$ vapour, Figure 5 . AFM-IR spectra were obtained by stepping the wavelength of incident infrared illumination through the $2400 \mathrm{~cm}^{-1}-3600 \mathrm{~cm}^{-1}$ range and recording the amplitude of thermally induced cantilever oscillations, Scheme 3 and Figure 5. For infrared mapping, the pulsed incident beam was held at $2550 \mathrm{~cm}^{-1}$, and the induced amplitude of cantilever oscillation was recorded during a contact mode scan. Under ambient conditions (prior to the introduction of $\mathrm{D}_{2} \mathrm{O}$ vapour into the sample chamber) a degree of background absorbance was detected at $2550 \mathrm{~cm}^{-1}$, however infrared amplitude mapping demonstrated that the intensity of this absorbance does not vary across the sample, Figure $5 \mathrm{a}-\mathrm{c}$. In the presence of $\mathrm{D}_{2} \mathrm{O}$ vapour $\left(50 \% \mathrm{RH}\right.$ at $\left.25{ }^{\circ} \mathrm{C}\right)$ the intensity of detected infrared absorbance (i.e., the amplitude of induced oscillations) at $2550 \mathrm{~cm}^{-1}$ increased, due to the presence of $\mathrm{D}_{2} \mathrm{O}$ adsorbed from the humid atmosphere. The location of this enhanced absorbance thus gives an indication of the surface hydrophilicity. Infrared amplitude mapping demonstrated that a higher concentration of deuterium oxide was adsorbed onto pore walls, indicating these regions are more wettable (hydrophilic) than the surrounding resin, Figure $5 d-f$. Finally, following analysis under humid conditions, silica desiccant was placed in the sample chamber and the specimen was allowed to dry for $48 \mathrm{~h}$. Subsequently, spectra revealed that the infrared absorbance at $2550 \mathrm{~cm}^{-1}$ (corresponding to the O-D stretch) returned to its original intensity, and greatly reduced contrast was observed in infrared amplitude images, Figure $5 \mathrm{~g}$-i. This demonstrates that the detected deuterium oxide species are desorbed from the sample surface, without affecting the coating structure (note that height profiles remain unchanged throughout, demonstrating that no further deformation occurs during exposure to humid conditions). 

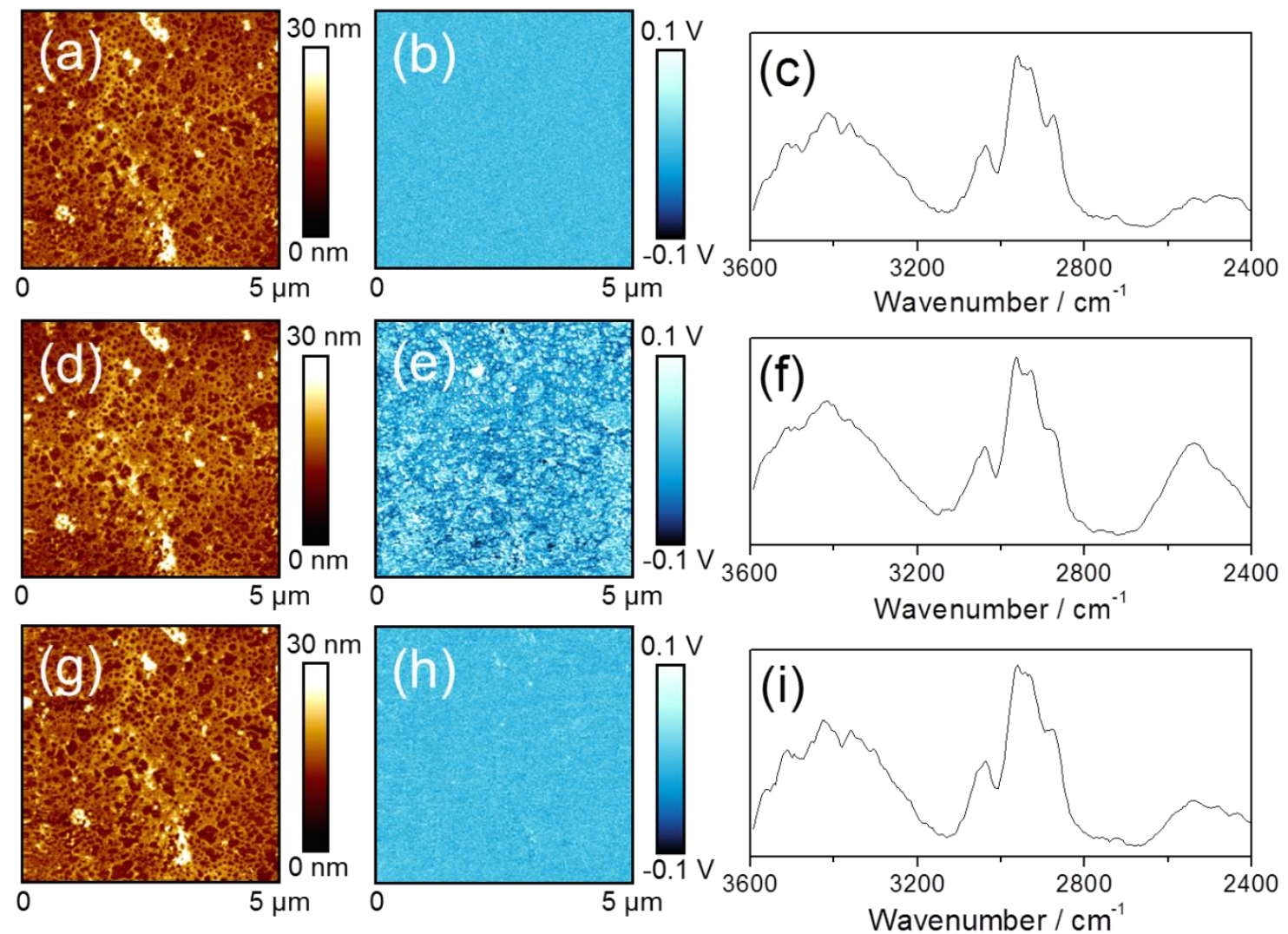

Figure 5. AFM-IR images and spectra of an epoxy-phenolic coating on polished carbon steel after 21 day immersion in deionised water and drying. AFM-IR height profiles, the corresponding infrared amplitude maps (at $2550 \mathrm{~cm}^{-1}$ ), and spectra obtained under (a) ambient conditions (30\% RH); (b) raised humidity after exposure to $\mathrm{D}_{2} \mathrm{O}$ vapour $(50 \% \mathrm{RH})$ and (c) after drying for $48 \mathrm{~h}(20 \% \mathrm{RH})$. Infrared amplitude maps have been flattened line-by-line about zero to show only local fluctuations in thermally induced amplitude. 


\section{DISCUSSION}

The Nguyen model of intact coating degradation entails the establishment of hydrophilic pathways through an organic coating as a precursor to the ionic transport channels necessary for corrosion onset.[8] It was proposed therein that organic coatings contain intrinsic 'hydrophilic' regions, predicted to be of low molecular weight (i.e., partially reacted or hydrolysed), or else regions of low cross-link density within the polymer network, through which water and ion transport freely occur. Corrosion is then thought to initiate when stress relaxation of the polymer joins these hydrophilic regions to create a percolating pathway through the coating. However, for the epoxy-phenolic coatings studied here, the presence of partially reacted low molecular weight material may be discounted, since the can coatings are shown to be fully cured (confirmed by the absence of any epoxy absorbance at $916 \mathrm{~cm}^{-1}$ in FTIR spectra, Figure 1, and no endothermic peak associated with excess cure observed in DSC thermograms, reported previously[31]). Furthermore, the absence of hydrolysis reactions was here confirmed using in-situ FTIR analysis during immersion, Figure 1, and leaching effects were ruled out using gravimetric analysis. It is, on the other hand, well established that nanoscale fluctuations in cross-linking density do occur within thermoset epoxy resins.[33-35] Furthermore, we have previously shown that short term water uptake into model epoxy-phenolic resins is indeed heterogeneous at the nanoscale, and corresponds to slight variations in the degree of cross-linking density, in keeping with the Nguyen model.[16] Since water has been shown to diffuse through the intact coatings rapidly, it is feasible that the distribution of free-volume voids provided by these fluctuations in cross-link density provide favourable diffusive pathways through the coating. Furthermore, we have found that water sorption during immersion does indeed induce polymeric relaxation as a consequence of water plasticisation, in keeping with numerous previously reported studies.[36-38] However, it is important to note that this process is in itself associated with deformation of the coating, as water binds to hydrogen-bonding sites exposed along the relaxing chain and disrupts the long range network structure. In the present case, this manifests in the development of hydrophilic pores and swollen regions capable of retaining water. This is in keeping with a study by MacQueen and Granata, where free volume cavities measured using positron annihilation lifetime spectroscopy (PALS) were found to increase in size during water uptake into unpigmented epoxy coatings. Thus, an important distinction with the Nguyen hypothesis is that long-term water sorption (and the associated plasticisation of the polymer network) appears to drive the creation of hydrophilic regions, rather than simply joining pre-existing heterogeneities within the network. 
It can readily be envisioned that these macroscopic hydrophilic regions may form a percolating network during long-term immersion, in keeping with the Nguyen model of coating degradation. However, at no point during ion permeation experiments was a sudden increase in conductivity measured, as would be expected if a channel capable of supporting rapid ionic transport were to spontaneously form. Furthermore, it is important to note that prior to any deformation due to water sorption (detectable only after several days immersion[15]), ion transport was already found to occur across the intact coatings, indicating that ion penetration is not wholly dependent on water-induced degradation. Similarly, sodium ion diffusion has previously been reported to proceed slowly through intact polyester coatings, but preferentially though defects.[39][40] It is feasible that ion transport is locally accelerated following water induced morphological changes in the polymer coating, and this may correspond to corrosion onset. However for corrosion initiation, further parameters to consider include bonding at the coating-substrate interface and substrate potentials driving ion transport (rather than a concentration gradient). Finally, an important result in the present study is the lack of evidence for direct ion-induced degradation. Whilst ionic species were shown to penetrate the resin, the level of sample deformation in fact appears to be lower for coatings exposed to electrolyte, in keeping with a mechanism of water-induced deformation (since significantly less water sorption occurs into films exposed to electrolyte vs. deionised water), Figures 1 and 4.

\section{CONCLUSIONS}

The chemical and morphological changes taking place within an epoxy-phenolic can-coating were investigated during immersion in aqueous electrolyte or water. In situ FTIR analysis confirmed the absence of hydrolysis reactions during prolonged immersion, accompanied by a non-Fickian water sorption process associated with network disruption, plasticisation and swelling. Ex-situ microscopy techniques revealed that this corresponds to the development of a hydrophilic porous structure. Comparable results were obtained for samples immersed in electrolyte, indicating that the ionic species do not significantly affect the mechanism of coating degradation.

\section{ACKNOWLEDGEMENTS}

The Authors are grateful to AkzoNobel for financial support and materials. 


\section{REFERENCES}

[1] M. Doherty, J.M. Sykes, Corros. Sci. 46 (2004) 1265.

[2] W. Fürbeth, M. Stratmann, Corros. Sci. 43 (2001) 207.

[3] W. Fürbeth, M. Stratmann, Prog. Org. Coatings 39 (2000) 23.

[4] B. Reddy, M.J. Doherty, J.M. Sykes, Electrochim. Acta 49 (2004) 2965.

[5] B. Reddy, J.M. Sykes, Prog. Org. Coatings 52 (2005) 280.

[6] A.P. Nazarov, D. Thierry, Prot. Met. Phys. Chem. Surfaces 45 (2009) 735.

[7] A. Nazarov, M.-G. Olivier, D. Thierry, Prog. Org. Coatings 74 (2012) 356.

[8] T. Nguyen, J.B. Hubbard, J.M. Pommersheim, J. Coatings Technol. 68 (1996) 45.

[9] Z.W. Wicks, F.N. Jones, S.P. Pappas, D.A. Wicks, Organic Coatings Science and Technology, 3rd ed., Wiley-Interscience, Hoboken, NJ, 2007.

[10] T. Yoshida, M. Horie, Y. Hoshino, H. Nakazawa, Food Addit. Contam. 18 (2001) 69.

[11] C.-M. Chang, C.-C. Chou, M.-R. Lee, Anal. Chim. Acta 539 (2005) 41.

[12] J.-H. Kang, F. Kondo, Res. Vet. Sci. 73 (2002) 177.

[13] P. Moongkhamklang, S.. Taylor, Prog. Org. Coatings 46 (2003) 259.

[14] S.R. Taylor, F. Contu, R. Santhanam, P. Suwanna, Prog. Org. Coatings 73 (2012) 169.

[15] S. Morsch, S. Lyon, P. Greensmith, S.D. Smith, S.R. Gibbon, Faraday Discuss. 180 (2015) 1.

[16] S. Morsch, S. Lyon, S.D. Smith, S.R. Gibbon, Prog. Org. Coatings 86 (2015) 173.

[17] H. Leidheiser, R.D. Granata, R. Turoscy, Corros. NACE 43 (1987) 296.

[18] W.S. Tait, K.A. Handrich, Corrosion 50 (1994) 373.

[19] B. Lahiri, G. Holland, A. Centrone, Small 9 (2013) 439.

[20] A. Dazzi, F. Glotin, R. Carminati, J. Appl. Phys. 107 (2010) 124519.

[21] K. Kjoller, J.R. Felts, D. Cook, C.B. Prater, W.P. King, Nanotechnology 21 (2010) 185705.

[22] B. Van Eerdenbrugh, M. Lo, K. Kjoller, C. Marcott, L.S. Taylor, J. Pharm. Sci. 101 (2012) 2066. 
[23] C. Mayet, A. Dazzi, R. Prazeres, J.-M. Ortega, D. Jaillard, Analyst 135 (2010) 2540.

[24] T. Nguyen, E. Byrd, D. Bentz, C. Lin, Prog. Org. Coatings 27 (1996) 181.

[25] D. Lin-Vien, N.B. Colthup, W.G. Fateley, J.G. Grasselli, The Handbook of Infrared and Raman Characteristic Frequencies of Organic Molecules, Academic Press Ltd, London, 1991.

[26] S. Cotugno, G. Mensitieri, P. Musto, L. Sanguigno, Macromolecules 38 (2005) 801.

[27] Y.C. Lin, X. Chen, Polymer 46 (2005) 11994.

[28] S. Roy, W.X. Xu, S.J. Park, K.M. Liechti, J. Appl. Mech. 67 (2000) 391.

[29] M.R. Vanlandingham, R.F. Eduljee, J.W. Gillespie, J. Appl. Polym. Sci. 71 (1999) 787.

[30] A. Mubashar, I.A. Ashcroft, G.W. Critchlow, A.D. Crocombe, J. Adhes. 85 (2009) 711.

[31] S. Morsch, S. Lyon, P. Greensmith, S.D. Smith, S.R. Gibbon, Prog. Org. Coatings 78 (2015) 293.

[32] T. Nguyen, E. Byrd, C. Lin, J. Adhes. Sci. Technol. 5 (1991) 697.

[33] C. Sahagun, S. Morgan, ACS Appl. Mater. Interfaces 4 (2012) 564.

[34] X. Gu, T. Nguyen, M. Oudina, D. Martin, B. Kidah, J. Jasmin, A. Rezig, L. Sung, E. Byrd, J.W. Martin, D.L. Ho, Y.C. Jean, JCT Res. 2 (2005) 547.

[35] C. Sahagun, K.M. Knauer, S.E. Morgan, J. Appl. Polym. Sci. 126 (2012) 1394.

[36] C. Wu, W. Xu, Polymer 48 (2007) 5440.

[37] T.C. Wong, L.J. Broutman, Polym. Eng. Sci. 25 (1985) 521.

[38] L.-R. Bao, A.F. Yee, C.Y.-C. Lee, Polymer 42 (2001) 7327.

[39] F. Deflorian, S. Rossi, J. Adhes. Sci. Technol. 17 (2003) 291.

[40] F. Deflorian, S. Rossi, Electrochim. Acta 51 (2006) 1736. 